\title{
PEMBERDAYAAN IBU RUMAH TANGGA DALAM DIVERSIFIKASI BUAH NAGA TIDAK LAYAK JUAL (GRADE B DAN C)
}

\section{Empowerment Of Housewives In Diversification Of Inappropriate Dragon Fruit (Grades $B$ and $C$ )}

\author{
Sylvia Dwi Wahyuni, Rista Fauziningtyas, Setho Hadisuyatmana \\ Fakultas Keperawatan Universitas Airlangga \\ sylvia.dwiwahyuni@fkp.unair.ac.id
}

\begin{abstract}
ABSTRAK
Tren produksi buah naga di Banyuwangi mengalami peningkatan setiap tahun. Jenis buah naga yang banyak dibudidayakan adalah buah naga merah. Hasil panen buah naga warga Glagah Agung dijual pada pengepul. Harga jual buah naga dari petani pada pengepul jauh dibawah harga jual kepada konsumen. Selain itu, harga jual buah naga dengan grade B dan C hampir setengah dari harga jual buah naga grade A dan ketika panen raya buah naga grade $\mathrm{B}$ dan $\mathrm{C}$ tidak laku dijual sehingga dibuang di belakang pekarangan rumah warga, menjadi pakan ternak sapi atau kambing atau dibuang ke sungai. Sementara itu, sebagian besar ibu di Desa Glagah Agung merupakan ibu rumah tangga yang belum produktif secara ekonomi. Para ibu mengeluh tidak memiliki keterampilan dan pengetahuan yang cukup untuk mengolah buah naga sehingga buah naga grade B dan C dibiarkan begitu saja sampai busuk. Selain itu, para ibu membutuhkan informasi terkait pembukuan sederhana untuk memulai usaha, penghitungan laba rugi serta cara untuk memasarkan produk, khususnya secara online. Metode yang digunakan untuk pemberdayaan adalah kerjasama dengan petani buah naga sebagai penyedia bahan baku buah naga grade B dan C, pelatihan pembuatan jenang dan sirup, pelatihan pengemasan jenang dan sirup, pengadaan fasilitas pembuatan jenang dan sirup, pelatihan manejemen pembukuan sederhana, dan pembuatan media pemasaran online melalui instagram, fanspage, dan tokopedia. Luaran pengmas ini adalah produk sirup dan jenang buah naga, publikasi ilmiah pada jurnal ber ISSN/prosiding, publikasi pada media cetak/online, peningkatan penerapan IPTEK di masyarakat, penerapan inovasi baru, dan penerapan metode pembuatan jenang dan sirup.
\end{abstract}

Kata kunci: diversifikasi, buah naga, ibu rumah tangga

\begin{abstract}
Dragon fruit production trends in Banyuwangi are increasing every year. The type of dragon fruit that is widely cultivated is the red dragon fruit. The harvest of Glagah Agung residents is sold to collectors. The selling price of dragon fruit from farmers at collectors is far below the selling price to consumers. In addition, dragon fruit with grade $\mathrm{B}$ and $\mathrm{C}$ is almost half of the selling price of grade $\mathrm{A}$ dragon fruit and when harvesting the quality of dragon fruit grade B and C is not sold so it is disposed of behind the yard of a resident's house, fed to cattle or goats or thrown into the river. Meanwhile, most of the mothers in Glagah Agung Village are housewives who are not yet economically productive. The mothers complained that they did not have sufficient skills and knowledge to process the dragon fruit so that the dragon fruits grade $\mathrm{B}$ and $\mathrm{C}$ were left to rot. In addition, mothers need information related to simple bookkeeping to start a business, the calculation of profit and loss and how to market their products, especially online. The method used for empowerment is collaboration with dragon fruit farmers as a provider of grade B and C dragon fruit raw materials, training in making jenang and syrup, training in jam and syrup packaging, procurement of jenang and syrup manufacturing facilities, training in simple bookkeeping management, and making marketing media online via Instagram, fanspage, and Tokopedia. The outcomes of this community service are dragon fruit syrup and jenang products, scientific publications in ISSN journals / proceedings, publications in print / online media, increasing the application of science and technology in society, applying new innovations, and applying the methods of making jenangs and syrups.
\end{abstract}

ABSTRACT

\section{PENDAHULUAN}

Buah naga memiliki penampilan

yang menarik, rasa asam manis menyegarkan dan memiliki beragam manfaat untuk kesehatan (Sutomo, 2007). Manfaat buah naga menurut (Marhazlina, 
2008) adalah sebagai anti hiperkolesterolemik. Sementara itu, Pedreno dan Escribano (2001) menyatakan bahwa buah naga berpotensi sebagai anti radikal bebas karena mengandung betasianin. Buah naga yang paling diminati konsumen dewasa ini adalah jenis buah naga merah (Hylocereus polyrhiruz) karena buah naga merah ini memiliki rasa lebih manis tanpa rasa langu dibanding jenis lainnya.

Buah Naga merupakan komoditas unggulan Indonesia dengan produksi terbanyak di Banyuwangi. Buah naga telah menjadi bagian masyarakat banyuwangi, khususnya banyuwangi selatan, begitu pula di desa Glagah Agung Kecamatan Purwoharjo. Pohon buah naga hampir ada di setiap pekarangan atau lahan kosong di sekitar rumah warga. Jenis buah naga yang banyak dibudidayakan adalah buah naga merah.

Tren produksi buah naga di Banyuwangi mengalami peningkatan setiap tahun. Data Dinas Pertanian (Disperta) Banyuwangi pada tahun 2015, total luas lahan tanaman buah naga 1.213,3 ha dengan jumlah produksi buah naga sebanyak 30.454 ton atau setara 251 kuintal per ha. Sementara itu, tahun 2016 luas tanaman buah naga meningkat menjadi 1.275,5 ha. Pada periode yang sama, total produksi buah naga di Bumi Blambangan meningkat menjadi 39.990 ton. Produktivitas tanaman buah naga di Banyuwangi tahun 2016 mencapai 313,5 kuintal per ha. Tren peningkatan produktivitas buah naga berlanjut di tahun berikutnya. Luas tanaman buah naga pada tahun 2017 tidak mengalami perubahan dibanding 2016, yaitu mencapai 1.275,5 ha. Namun, total produksi buah naga selama 2017 mencapai 42.349 ton. Angka tersebut menunjukkan produktivitas tanaman buah naga di tahun 2017 mencapai 332 kuintal per ha. (Sodikin A, 2018)

Hasil panen buah naga warga Purwoharjo dijual pada pengepul. Harga jual buah naga dari petani pada pengepul jauh dibawah harga jual kepada konsumen. Selain itu, buah naga dengan grade B dan C akan dibeli dengan harga hampir setengah dari buah naga grade $A$. Hal tersebut semakain parah pada saat panen raya karena buah naga grade $\mathrm{B}$ dan $\mathrm{C}$ tidak laku dijual. Hasil panen buah naga pasti terdiri dari grade A, B, dan C. Selain itu, belum terdapat produk olahan buah naga yang dapat dihasilkan warga sekitar sehingga hasil panen hanya dijual dengan harga yang disepakati pengepul. Hasil wawancara dengan mitra dan observasi tampak hasil panen buah naga grade $\mathrm{B}$ dan $\mathrm{C}$ yang dibuang di pekarangan belakang rumah warga. Selain itu, buah naga tersebut juga dijadikan makanan ternak sapi atau kambing, dan sebagian dibuang ke sungai. Sebenarnya buah naga tersebut layak konsumsi tetapi tidak laku dijual sehingga warga memilih solusi di atas dengan tujuan tidak menambah masalah ketika membiarkan buah naga tersebut busuk di depan atau di dalam rumah mereka.

Sementara itu, hasil wawancara dengan ketua RT 08 dan observasi didapati sebagian besar ibu di Desa Glagah Agung merupakan ibu rumah tangga yang belum produktif secara ekonomi. Kegiatan para ibu setiap hari adalah mengurus rumah, membantu para suami, mengurus anak, mengurus ternak yang dimiliki, atau berbincang-bincang dengan sesama ibu diwaktu luang mereka. Masih terdapat banyak waktu luang yang dapat dimanfaatkan untuk kegiatan yang lebih produktif dan bernilai ekonomi.

Para ibu juga mengeluh tidak memiliki keterampilan dan pengetahuan yang cukup untuk mengolah buah naga sehingga buah naga grade $\mathrm{B}$ dan $\mathrm{C}$ dibiarkan begitu saja sampai busuk. Mereka juga berharap terdapat bantuan dari instansi pemerintah untuk mengatasi masalah pembuangan buah naga yang tidak laku dijual. Selain itu, para ibu membutuhkan informasi terkait pembukuan sederhana untuk memulai usaha serta cara untuk memasarkan produk, khususnya secara online. Sementara itu, hasil wawancara dengan ketua RT.8 didapatkan informasi bahwa terdapat balai desa yang dapat digunakan untuk pertemuan warga dalam jumlah banyak. Balai tersebut dapat dijadikan tempat pelatihan progam pengmas 
terkait pengolahan produk buah naga.

\section{METODE}

Metode yang digunakan dalam pemberdayaan masayarakat ini adalah sebagai berikut:

1. Kerjasama dengan petani buah naga untuk menyuplai bahan baku berupa buah naga grade $\mathrm{B}$ dan $\mathrm{C}$.

2. Pelatihan membuat dan mengemas sirup dan jenang buah naga.

3. Pengadaan sarana dan fasilitas pelatihan keterampilan membuat sirup dan jenang buah naga.

4. Pelatihan manajemen pembukuan sederhana untuk membuka usaha penjualan sirup dan jenang buah naga

5. Pelatihan manajemen menghitung laba rugi

6. Pelatihan membuat instagram dan fanspage.

Adapun rincian kegiatan dijelaskan dalam tabel 1 berikut:

\begin{tabular}{|c|c|c|}
\hline Kegiatan & $\begin{array}{c}\text { Bentuk } \\
\text { Kegiatan }\end{array}$ & $\begin{array}{c}\text { Partisipasi } \\
\text { Mitra }\end{array}$ \\
\hline $\begin{array}{l}\text { Kerjasama } \\
\text { dengan petani } \\
\text { buah naga } \\
\text { untuk } \\
\text { menyuplai } \\
\text { bahan baku } \\
\text { berupa buah } \\
\text { naga grade B } \\
\text { dan C. }\end{array}$ & $\begin{array}{l}\text { Diskusi mengenai } \\
\text { Kerjasama dengan } \\
\text { petani buah naga } \\
\text { milik warga sekitar }\end{array}$ & $\begin{array}{l}\text { Perkebunan } \\
\text { buah naga } \\
\text { milik } \\
\text { warga } \\
\text { untuk } \\
\text { menyuplai } \\
\text { bahan baku } \\
\text { sirup dan } \\
\text { jenang } \\
\text { buah naga } \\
\text { grade B } \\
\text { dan C }\end{array}$ \\
\hline $\begin{array}{l}\text { Pelatihan } \\
\text { membuat dan } \\
\text { mengemas } \\
\text { sirup dan } \\
\text { jenang buah } \\
\text { naga }\end{array}$ & $\begin{array}{l}\text { Pelatihan } \\
\text { pembuatan selai } \\
\text { dan } \\
\text { jenang.sebanyak } 6 \\
\text { kali pertemuan @ } 2 \\
\text { jam di Balai Desa } \\
\text { Glagah Agung } \\
\text { Banyuwangi. }\end{array}$ & $\begin{array}{l}\text { Para Ibu } \\
\text { rumah } \\
\text { tangga } \\
\text { hadir dan } \\
\text { berpartisipa } \\
\text { si aktif } \\
\text { dalam } \\
\text { setiap } \\
\text { kegiatan } \\
\text { selama } \quad 6 \\
\text { kali } \\
\text { pertemuan. }\end{array}$ \\
\hline Pengadaan & Kegiatan & Aktif \\
\hline
\end{tabular}

\begin{tabular}{lll}
\hline sarana dan & pengadaan & mendukung \\
fasilitas & peralatan dan & pengadaan \\
pelatihan & bahan $\quad$ untuk & alat dan \\
keterampilan & membuat sirup dan & berkemaua \\
membuat & jenang. & $\mathrm{n}$ keras \\
sirup dan & & untuk \\
jenang buah & & belajar \\
naga serta & & menggunak \\
mengemas ke & & an \\
dalam botol & & peralatan \\
kaca bagi ibu & & tersebut
\end{tabular}

rumah

tangga.

\begin{tabular}{|c|c|}
\hline $\begin{array}{l}\text { Pelatihan } \\
\text { manajemen } \\
\text { pembukuan } \\
\text { sederhana } \\
\text { untuk } \\
\text { membuka } \\
\text { usaha } \\
\text { penjualan } \\
\text { sirup dan } \\
\text { jenang buah } \\
\text { naga }\end{array}$ & \begin{tabular}{lrl}
\multicolumn{2}{l}{ Memberikan } & Hadir dan \\
informasi kepada & berperan \\
para ibu rumah & aktif dalam \\
tangga & agar & kegiatan \\
memiliki & pelatihan \\
kemampuan & manajemen \\
manajemen & pembukuan \\
pembukuan & sederhana \\
sederhana untuk & yang \\
membuka usaha & diadakan \\
penjualan sirup dan & \\
jenang buah naga. &
\end{tabular} \\
\hline $\begin{array}{l}\text { Pelatihan } \\
\text { menghitung } \\
\text { laba dan rugi } \\
\text { untuk } \\
\text { membuka } \\
\text { usaha } \\
\text { penjualan } \\
\text { sirup dan } \\
\text { jenang buah } \\
\text { naga }\end{array}$ & $\begin{array}{lrl}\begin{array}{l}\text { Kegiatan } \\
\text { dilakukan }\end{array} \text { yang } & \begin{array}{l}\text { Hadir dan } \\
\text { untuk }\end{array} & \begin{array}{l}\text { berperan } \\
\text { memberikan }\end{array} \\
\text { membif dalam } \\
\text { informasi kepada } & \text { kegiatan } \\
\text { para ibu rumah } & \text { pelatihan } \\
\text { tangga } & \text { agar } & \text { menghitung } \\
\text { memiliki } & & \text { laba rugi } \\
\text { kemampuan } & & \text { yang } \\
\text { menghitung } \quad \text { laba } & \text { diadakan } \\
\text { rugi } & \text { untuk } & \\
\text { membuka usaha } & \\
\text { penjualan sirup dan } & \\
\text { jenang buah naga } & \end{array}$ \\
\hline $\begin{array}{l}\text { Membuat } \\
\text { instagram dan } \\
\text { fanspage }\end{array}$ & $\begin{array}{lrl}\text { Kegiatan } & \text { diskusi } & \text { Hadir dan } \\
\text { mengenai } & \text { kriteria- } & \text { berperan } \\
\text { kriteria yang harus } & \text { aktif dalam } \\
\text { dipenuhi } & \text { tentang } & \text { kegiatan } \\
\text { kualitas } & \text { produk } & \text { pembuatan } \\
\text { yang } & \text { dapat } & \text { instagaram } \\
\text { dipasarkan } & \text { secara } & \text { dan } \\
\text { online } & & \text { fanspage } \\
\end{array}$ \\
\hline \multicolumn{2}{|c|}{$\begin{array}{l}\text { HASIL DAN PEMBAHASAN } \\
\text { Pelatihan pembukuan sederhana dan } \\
\text { pemasaran melalui media online } \\
\text { Kegiatan pelatihan dilakukan } \\
\text { selama } 2 \text { jam. Pengukuran pengetahuan } \\
\text { peserta melalui pre test dan post test. } \\
\text { Pelatihan dilaksanakan melalui metode } \\
\text { wawancara dan praktik langsung sehingga }\end{array}$} \\
\hline
\end{tabular}


peserta pengetahuan peserta meningkat secara signifikan. Secara umum, pengetahuan awal peserta terkait media online lebih tinggi dibandingakn pengetahuan tentang pembukuan sederhan.

Hasil perbandingan pre test dan post test pada kedua materi tersebut disajikan dalam tabel 2 berikut:

\begin{tabular}{|c|l|l|l|l|}
\hline Peserta & \multicolumn{2}{|c|}{$\begin{array}{c}\text { Materi 1 } \\
\text { (pembukuan } \\
\text { sederhana) }\end{array}$} & \multicolumn{2}{c|}{$\begin{array}{c}\text { Materi 2 } \\
\text { (pemasaran } \\
\text { online) }\end{array}$} \\
\cline { 2 - 5 } & Pre & Post & Pre & Post \\
\hline 1 & 70 & 90 & 100 & 100 \\
\hline 2 & 30 & 50 & 87,5 & 100 \\
\hline 3 & 60 & 60 & 100 & 100 \\
\hline 4 & 60 & 70 & 62,5 & 87,5 \\
\hline 5 & 50 & 70 & 75 & 87,5 \\
\hline 6 & 70 & 90 & 100 & 100 \\
\hline 7 & 80 & 90 & 100 & 100 \\
\hline 8 & 70 & 90 & 62,5 & 75 \\
\hline 9 & 70 & 90 & 87,5 & 87,5 \\
\hline 10 & 30 & 50 & 67,5 & 75 \\
\hline 11 & 60 & 80 & 75 & 100 \\
\hline 12 & 40 & 60 & 62,5 & 87,5 \\
\hline 13 & 50 & 60 & 87,5 & 87,5 \\
\hline 14 & 60 & 90 & 75 & 87,5 \\
\hline 15 & 60 & 80 & 75 & 75 \\
\hline & & & & \\
\hline
\end{tabular}

\section{Produk sirup dan jenang buah naga}

Pelatihan pengolahan buah naga berupa sirup dan jenang diawali dengan penjelasan pembicara terkait alat dan bahan serta tahapan pembuatan. Kemudian, peserta melakukan praktik bersama dengan pendampingan pembicara dan tim pengabdian kepada masyarakat. Hasil kegiatan berupa produk sirup buah naga dengan varian rasa dan varian sirup buah naga tanpa biji dan dengan biji serta jeannag buah naga.

\section{Publikasi kegiatan di media online}

Kegiatan pengmas buah naga ini telah dipublikasikan di:

1. Tribun Jatim

https://jatim.tribunnews.com/2019/0

7/15/ajari-olah-limbah-buah-naga- departemen-jiwa-komunitas-fkpunair-berdayakan-ibu-ibu-dibanyuwangi

2. Unair News http://news.unair.ac.id/2019/07/12/pe ngmas-dosen-fkp-unair-berdayakanpetani-buah-naga-di-banyuwangi/

3. Ners News (http://ners.unair.ac.id/site/index.php /news-fkp-unair/315-peningkatannilai-ekonomi-buah-naga-yang-taklaku-dijual-menuju-kemandirianekonomi-rumah-tangga).

\section{KESIMPULAN}

1. Pentingnya pendampingan pada ibu rumah tangga untuk memberdayakan mereka dalam usaha pengolahan buah naga yang berpotensi ekonomi.

2. Pelatihan pembukuan sederhana dan pemasaran secara online melalui wawancara dan praktik langsung dapat meningkatkan pengetahuan peserta secara signifikan.

\section{SARAN}

Perlu dilakukan evaluasi tingkat pemahaman peserta terhadap materi pembuatan jenang dan sirup yang telah diajarkan serta cara pemasaran produk tersebut. Selain itu, pendampingan lebih lanjut diperlukan agar masyarakat mampu mengembangkan keterampilan mengolah buah naga menjadi produk lain yang memiliki nilai jual yang tinggi dan dapat dijadikan sebagai sebuah usaha yang menjanjikan dalam meningkatkan perekonomian masyarakat setempat.

\section{DAFTAR PUSTAKA}

A, Sodiqin. 2018 Produktivitas Buah Naga Meningkat. [Online]. Available: https://radarbanyuwangi.jawapos.co $\mathrm{m} / \mathrm{read} / 2018 / 11 / 07 / 102180 /$ produktiv itas-buah-naga-banyuwangi-terusmeroket-begini-caranya. 
Fitri, Elpida ; Harun ,Noviar, dan Johan, V.S. 2017. Konsentrasi Gula Dan Sari Buah Terhadap Kualitas Sirup Belimbing Wuluh (Averrhoa bilimbi L.) JOM Faperta UR Vol. 4 No. 1 Februari 2017

Marhazlina, M. 2008. Departement of Nutrition and Dietetic Faculty of Medicine and Health Sciences. University Putra, Malaysia.
Pedreno, M.A. and J. Escribano. 2001. "Corelation between antiradical activity and stability of Betanine from Beta vulgaris L. roots under different $\mathrm{pH}$, temperature and light conditions". Journal of the science of food and agriculture, 81(7): 627-631

Sutomo, Budi. (2007). Buah Naga Merah Segar dan Berkhasiat. Jakarta. Penebar Swadaya 